\title{
Pharmacokinetic studies of meloxicam following oral and transdermal administration in Beagle dogs
}

\author{
Yue YUAN ${ }^{1}$, Xiao-yan $\mathrm{CHEN}^{2}$, San-ming $\mathrm{LI}^{1}$, Xiu-yan $\mathrm{WEI}^{1}$, Hui-min $\mathrm{YAO}^{1}$, Da-fang $Z \mathrm{HONG}^{2, *}$ \\ ${ }^{1}$ Shenyang Pharmaceutical University, Shenyang 110016, China; ${ }^{2}$ Shanghai Institute of Materia Medica, Chinese Academy of Sciences, \\ Shanghai 201203, China
}

\begin{abstract}
Aim: The potential for topical delivery of meloxicam was investigated by examining its pharmacokinetic profiles in plasma and synovial fluid following oral and transdermal administration in Beagle dogs.

Methods: The experiment was a two-period, crossover design using 6 Beagle dogs. Meloxicam tablets were administered orally at a dose of $0.31 \mathrm{mg} / \mathrm{kg}$, and meloxicam gel was administered transdermally at a dose of $1.25 \mathrm{mg} / \mathrm{kg}$. Drug concentrations in plasma and synovial fluid were determined by liquid chromatography-tandem mass spectrometry (LC/MS/MS). The pharmacokinetic parameters were calculated using the Topfit 2.0 program.

Results: The pharmacokinetic results showed that $\mathrm{AUC}_{0-\mathrm{t}}\left(23.9 \pm 8.26 \mu \mathrm{g} \cdot \mathrm{h} \cdot \mathrm{mL}^{-1}\right)$ in plasma after oral administration was significantly higher than after transdermal delivery $\left(1.00 \pm 0.43 \mu \mathrm{g} \cdot \mathrm{h} \cdot \mathrm{mL}^{-1}\right)$. In contrast, the ratio of the average concentration in synovial fluid to that in plasma following transdermal administration was higher than that for an oral delivery. The synovial fluid concentration in the treated leg was much higher than that in the untreated leg, whereas the synovial fluid concentration in the untreated leg was similar to the plasma concentration.

Conclusion: The high concentration ratio of synovial fluid to plasma indicates direct penetration of meloxicam following topical administration to the target tissue. This finding is further supported by the differences observed in meloxicam concentrations in synovial fluid in the treated and untreated joints at the same time point. Our results suggest that transdermal delivery of meloxicam is a promising method for decreasing its adverse systemic effects.
\end{abstract}

Keywords: meloxicam; pharmacokinetics; synovial fluid; cutaneous administration; liquid chromatography-tandem mass spectrometry

Acta Pharmacologica Sinica (2009) 30: 1060-1064; doi: 10.1038/aps.2009.73; published online 8 June 2009

\section{Introduction}

Meloxicam is a potent non-steroidal anti-inflammatory drug (NSAID) of the enolic acid class of oxicam derivatives. Its mode of action is via preferential inhibition of cyclo-oxygenase-2 (COX-2) activity and prostaglandin synthesis. Meloxicam has proven efficacy in treating rheumatoid arthritis, osteoarthritis, and many other joint diseases ${ }^{[1]}$. Although it has a good gastrointestinal tolerability compared with other NSAIDs, stomach upset and indigestion are common side effects. In addition, cardiac side effects are also suspected ${ }^{[2]}$. Consequently, meloxicam is not suitable for the treatment of rheumatological patients who also present with gastric ulcer ${ }^{[3]}$. In order to avoid irritation of the gastrointestinal tract and to minimize systemic toxicity, a topical transdermal formulation

* To whom correspondence should be addressed.

E-mail zhongdf@china.com

Received 2009-01-22 Accepted 2009-04-21 of meloxicam has been developed ${ }^{[4,5]}$.

The mechanism of the topical delivery of NSAIDs is still unclear. It is believed that local accumulation of the drug in target tissues could occur either by direct penetration or via redistribution through systemic circulation ${ }^{[6,7]}$. It has been suggested that drugs passing through the stratum corneum, epidermis, and dermis can be effectively removed by cutaneous microcirculation, which can act as a "sink" ${ }^{[8]}$. However, recent developments have now shown that local, targeted, subcutaneous drug delivery might be possible and effective ${ }^{[9]}$.

In this study, the mechanism of the topical delivery of meloxicam was investigated by examining the pharmacokinetic profiles of meloxicam in the plasma and synovial fluid (SF) of Beagle dogs following oral and topical administration of the drug.

\section{Materials and methods}

Chemicals and reagents

Meloxicam (99\% purity) and piroxicam (internal standard, 
99\% purity) were supplied by Taiyang Pharmaceutical Co, Ltd (Beijing, China). HPLC-grade methanol and acetonitrile were purchased from Kangkede Technology Co (Tianjin, China). Other reagents used were of analytical grade and were obtained commercially. Distilled water, prepared from demineralized water, was used throughout the study. Commercially available $7.5 \mathrm{mg}$ doses of meloxicam tablets (Mobic, Boehringer Ingelheim Ltd, Shanghai, China) were chosen as a reference. The formulation of meloxicam gel, containing $1 \%$ meloxicam in carbopol 940, was prepared in our laboratory.

\section{Preparation of the meloxicam gel}

Carbopol 940 (1.0 g) was dissolved in $40 \mathrm{~mL}$ of water, and the $\mathrm{pH} 7.5-8.0$ of the gel was adjusted using adequate triethanolamine. A $1.0 \mathrm{~g}$ quantity of meloxicam was dissolved in a minimal volume of a propylene glycol, alcohol and diethyleneglycol monoethyl ether (transcutol) mixture. The meloxicam solution was then added to the carbopol solution under vigorous stirring, and water was added to a final volume of $100 \mathrm{~mL}$.

\section{Animals and treatment}

Beagle dogs $(n=6$, both female and male, body weight $12 \pm 2 \mathrm{~kg}$ ) were supplied by the Lab Animal Center of Shenyang Kangping Institution (Certificate No SYXK 2003-0006). An open randomized two-way crossover study with a wash-out period of 5 weeks was conducted. The dogs were randomly assigned into two groups, a single po dose of $0.31 \mathrm{mg} / \mathrm{kg}$ meloxicam was given to one group, and the other group was given a single dose of $1.25 \mathrm{mg} / \mathrm{kg}$ meloxicam applied as a topical gel. All dogs were fed a standard laboratory chow with water and were fasted overnight before the experiment.

\section{Oral administration}

The dogs in this group were given a single dose of $0.31 \mathrm{mg} / \mathrm{kg}$ meloxicam, fed at $4 \mathrm{~h}$ post-dosing, and water was available from $2 \mathrm{~h}$ post-dosing onward. Approximately $0.5 \mathrm{~mL}$ of blood was withdrawn through the small saphenous vein of the hind leg prior to dosing and then again at $0.5,1,2,4,8,12,24,36$, 48,72 , and $96 \mathrm{~h}$ after the oral administration. Plasma was separated by centrifugation at $3000 \times g$ for $10 \mathrm{~min}$ and stored at $-20{ }^{\circ} \mathrm{C}$ until analysis.

After general anesthesia with thiopentone sodium, the dogs were placed in dorsal recumbency and the skin over the joints was aseptically prepared with $30 \%$ ethanol. The stifle joints were flexed maximally to tense the joint capsule and digital pressure was applied to the caudal aspect of the joint opposite the point of syringe entry. A 20 gauge, 1.5 inch needle on a $1 \mathrm{~mL}$ tuberculin syringe was inserted midway between the patella and the patellar ligament. The needle was advanced until no resistance could be felt, which indicated successful entry into the joint space. An SF sample of $50 \mu \mathrm{L}$ was collected from the stifle joints of the left and right hind legs, respectively, at 0 (predose), 4, 8, 12, 24, 48, 72, and $96 \mathrm{~h}$ post dose. The SF samples were stored at $-20^{\circ} \mathrm{C}$ until analysis.

\section{Topical administration}

Following the protocol used for a previous study ${ }^{[10]}$, one day prior to the experiment, the elbow and stifle joints of hind legs were carefully shaved. No visible signs of damage to the skin surface were observed. On the following day, a dose (1.25 mg/ kg meloxicam) of $1 \%$ meloxicam gel was uniformly applied over the shaved shin area $(7 \mathrm{~cm} \times 10 \mathrm{~cm})$ of the right hind leg joint and covered with a plastic film secured with adhesive tape. Eight hours after transdermal administration, the gel was removed from the joint and the skin was washed clean with $30 \%$ ethanol, followed by washing with soap solution and water. A blood sample of $0.5 \mathrm{~mL}$ was obtained at 0 (predose), 2, 4, 8, 12, 24, 36, 48, 72, and $96 \mathrm{~h}$ after topical dosing. An SF sample of $50 \mu \mathrm{L}$ was collected in the same way as described in the "Oral administration" section at 0 (predose), $8,12,24,48,72$, and $96 \mathrm{~h}$, respectively. All of the samples were stored at $-20^{\circ} \mathrm{C}$ until analysis.

\section{Analytical method}

In this study, meloxicam concentrations in plasma and synovial fluid were determined with a modified LC/MS/MS method based on our previous report ${ }^{[11]}$ using piroxicam as an internal standard (IS). Protein was precipitated from the samples by mixing a $25 \mu \mathrm{L}$ aliquot of plasma or SF, 25 $\mu \mathrm{L}$ of methanol (to maintain the same volume values as the calibration curves), $25 \mu \mathrm{L}$ of internal standard, and $75 \mu \mathrm{L}$ of methanol. The mixture was vortex-mixed for $30 \mathrm{~s}$, followed by centrifugation for $10 \mathrm{~min}$ at $3000 \times g$. The supernatant was processed to dryness under a stream of nitrogen, and the residue was reconstituted in $100 \mu \mathrm{L}$ of the mobile phase. A $20 \mu \mathrm{L}$ aliquot was injected into the LC/MS/MS system for analysis.

Separation was performed on a Zorbax SB $\mathrm{C}_{18}$ column (150 $\mathrm{mm} \times 4.6 \mathrm{~mm}$ ID, $5 \mu \mathrm{m}$, Agilent, USA), with a Security Guard $\mathrm{C}_{18}$ guard column $(4 \mathrm{~mm} \times 3.0 \mathrm{~mm}$ ID, Phenomenex, Torrance, CA, USA), using a mobile phase of acetonitrile-water-formic acid $(80: 20: 0.2, v / v / v)$ at a flow rate of $0.5 \mathrm{~mL} / \mathrm{min}$ at room temperature. Meloxicam and the piroxicam IS were detected using a Thermo Finnigan TSQ Quantum Ultra triple-quadrupole mass spectrometer (San Jose, CA, USA) equipped with an electrospray ionization (ESI) source.

\section{Pharmacokinetic analysis}

Meloxicam plasma concentration data for individual dogs were analyzed by non-compartmental analysis using the TopFit 2.0 software package (Thomae GmbH, Germany). The area under the curve $\left(\mathrm{AUC}_{0-\mathrm{t}}\right)$ was calculated using the linear-trapezoidal rule, with extrapolation to infinity $\left(\mathrm{AUC}_{0-\infty}\right)$ from the last detectable concentration. The relative bioavailability $(F)$ was determined as $F=\left(\mathrm{AUC}_{0-t}\right.$ (transdermal) $\left.\times 3.75\right)$ / $\left(\mathrm{AUC}_{0-\mathrm{t}(\text { oral })} \times 15\right) \times 100 \%$, using mean $\mathrm{AUC}_{0-t}$ values for the transdermal dose and oral dose. Differences in pharmacokinetic parameters were assessed using Student's $t$-test with $P<0.05$ being taken as significant.

The drug concentrations in SF and plasma at different time points for the six dogs were averaged to evaluate the $\mathrm{S} / \mathrm{P}$ ratio 
for meloxicam.

\section{Results}

\section{Method validation}

The assay was linear up to a concentration of $1000 \mathrm{ng} / \mathrm{mL}$, with a lower limit of quantification at $0.5 \mathrm{ng} / \mathrm{mL}$. The accuracy was expressed by (mean observed concentration)/(spiked concentration) $\times 100 \%$ and the precision by relative standard deviation (RSD). Both were within the acceptable range required by the FDA Guidance for Bioanalytical Method Validation.

\section{Pharmacokinetic parameters}

The mean concentration-time profiles of meloxicam in plasma and SF after oral and transdermal administration are shown in Figures 1 and 2. The corresponding pharmacokinetic parameters are listed in Tables 1 and 2. The dose-normalized pharmacokinetic parameters of meloxicam in Beagle dogs are listed in Table 3.

The pharmacokinetic parameters of meloxicam listed in

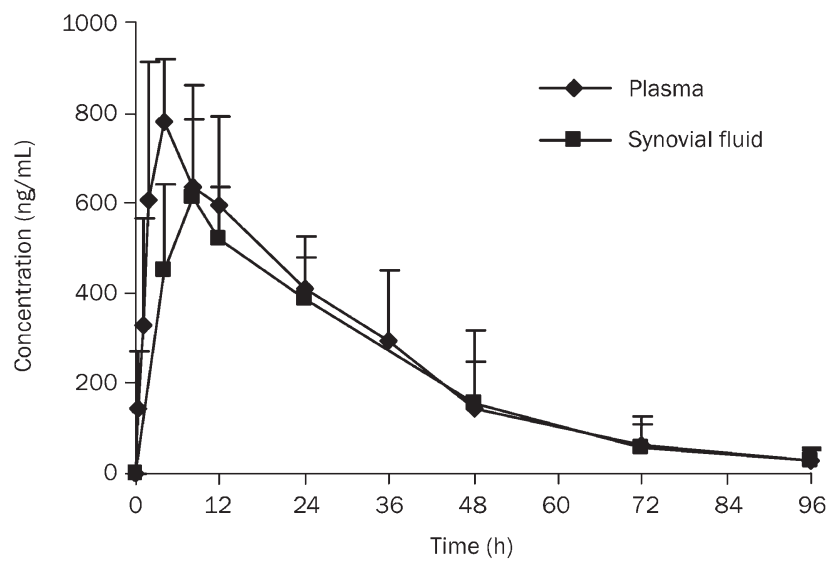

Figure 1. Mean concentration-time profiles of meloxicam in synovial fluid and plasma after an oral administration to Beagle dogs at $0.31 \mathrm{mg} / \mathrm{kg}$ $(n=6)$.

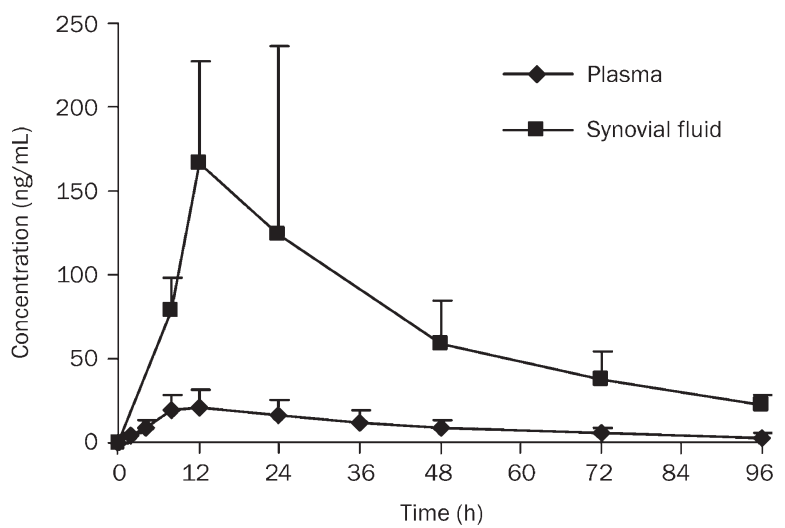

Figure 2. Mean concentration-time profiles of meloxicam in synovial fluid of the treated leg and in plasma after a transdermal administration to Beagle dogs at $1.25 \mathrm{mg} / \mathrm{kg}(n=6)$.
Table 1. Pharmacokinetic parameters of meloxicam in Beagle dogs after an oral administration at $0.31 \mathrm{mg} / \mathrm{kg}$. $n=6$. Mean $\pm S D$.

\begin{tabular}{lcc}
\hline \multicolumn{1}{c}{ Parameter } & \multicolumn{2}{c}{ Oral administration } \\
& Plasma & Synovial fluid \\
\hline$t_{1 / 2}(\mathrm{~h})$ & $17.5 \pm 5.43$ & $17.2 \pm 6.67$ \\
$t_{\max }(\mathrm{h})$ & $4.0 \pm 0.0$ & $6.7 \pm 2.0$ \\
$C_{\max }(\mathrm{ng} / \mathrm{mL})$ & $780 \pm 136$ & $648 \pm 163$ \\
$\mathrm{AUC} C_{0-\mathrm{t}}\left(\mu \mathrm{gg} \cdot \mathrm{h} \cdot \mathrm{mL}^{-1}\right)$ & $23.9 \pm 8.26$ & $22.0 \pm 7.31$ \\
$\mathrm{AUC} \mathrm{C}_{0-\infty}\left(\mu \mathrm{g} \cdot \mathrm{h} \cdot \mathrm{mL}^{-1}\right)$ & $24.8 \pm 8.56$ & $22.8 \pm 8.11$ \\
$\mathrm{MRT}(\mathrm{h})$ & $24.4 \pm 6.6$ & $24.7 \pm 5.90$ \\
$\mathrm{CL} / \mathrm{F}\left(\mathrm{mL} \cdot \mathrm{min}^{-1} \cdot \mathrm{kg}^{-1}\right)$ & $0.21 \pm 0.10$ & \\
$\mathrm{~V} / \mathrm{F}(\mathrm{L} / \mathrm{kg})$ & $0.32 \pm 0.10$ & \\
\hline
\end{tabular}

Table 2. Pharmacokinetic parameters of meloxicam in Beagle dogs after a transdermal administration at $1.25 \mathrm{mg} / \mathrm{kg}$. $n=6$. Mean \pm SD.

\begin{tabular}{lcc}
\hline \multicolumn{1}{c}{ Parameter } & \multicolumn{2}{c}{ Transdermal administration } \\
& Plasma & Synovial fluid \\
\hline$t_{1 / 2}(\mathrm{~h})$ & $36.6 \pm 6.96$ & $37.9 \pm 20.9$ \\
$t_{\max }(\mathrm{h})$ & $11.3 \pm 1.63$ & $14.0 \pm 4.90$ \\
$C_{\max }(\mathrm{ng} / \mathrm{mL})$ & $25.3 \pm 9.06$ & $202 \pm 93.0$ \\
$\mathrm{AUC} \mathrm{C}_{0-\mathrm{t}}\left(\mu \mathrm{g} \cdot \mathrm{h} \cdot \mathrm{mL}^{-1}\right)$ & $1.00 \pm 0.43$ & $6.93 \pm 3.54$ \\
$\mathrm{AUC} \mathrm{C}_{0-\infty}\left(\mu \mathrm{gg} \cdot \mathrm{h} \cdot \mathrm{mL}^{-1}\right)$ & $1.19 \pm 0.51$ & $8.19 \pm 3.51$ \\
$\mathrm{MRT}(\mathrm{h})$ & $36.1 \pm 4.17$ & $34.7 \pm 2.60$ \\
$\mathrm{CL} / \mathrm{F}\left(\mathrm{mL} \cdot \mathrm{min}^{-1} \cdot \mathrm{kg}^{-1}\right)$ & $19.2 \pm 7.51$ & \\
$\mathrm{~V} / \mathrm{F}(\mathrm{L} / \mathrm{kg})$ & $62.7 \pm 33.7$ & \\
\hline
\end{tabular}

Tables 1 and 2 show that the $\mathrm{AUC}_{0-\mathrm{t}}$ and $C_{\max }$ values were much lower in plasma after transdermal administration compared with those obtained after oral administration, with $C_{\max }$ of $25.3 \pm 9.1 \mathrm{ng} / \mathrm{mL}$ vs $780 \pm 136 \mathrm{ng} / \mathrm{mL}$, and $\mathrm{AUC}_{0-\mathrm{t}}$ of $1.00 \pm 0.43$ $\mu \mathrm{g} \cdot \mathrm{h} \cdot \mathrm{mL}^{-1}$ vs $23.9 \pm 8.26 \mu \mathrm{g} \cdot \mathrm{h} \mathrm{mL}^{-1}(P<0.05)$.

As shown in Figures 1 and 2, the SF concentrations of meloxicam were about $20 \%$ lower than the plasma concentrations after an oral dose, whereas the SF concentrations were about 8-fold higher than those in plasma after topical delivery.

SF concentrations of meloxicam in the treated (right) and untreated (left) joint of hind legs at different time points after transdermal administration are listed in Table 4. The SF concentration in the right leg was significantly higher than that in the left leg $(P<0.01)$. The concentration ratios of SF to plasma $(\mathrm{S} / \mathrm{P})$ after oral and transdermal administration were calculated and are shown in Figure 3.

\section{Discussion}

The relative bioavailability of meloxicam in the topical gel was $1.05 \%$ of the oral drug administration. The lower plasma concentration and drug exposure indicated that topical formulation could be used to avoid gastrointestinal irritation and decrease adverse systemic effects.

Although the systemic absorption was much lower, the $T_{\max }$ and MRT after transdermal administration were more prolonged than after oral administration in both plasma and SF. 
Table 3. The dose-normalized pharmacokinetic parameters of meloxicam in Beagle dogs after an oral dose of $0.31 \mathrm{mg} / \mathrm{kg}$ or a transdermal dose of 1.25 $\mathrm{mg} / \mathrm{kg}$. $n=6$. Mean \pm SD.

\begin{tabular}{|c|c|c|c|c|}
\hline \multirow{2}{*}{ Parameter } & \multicolumn{2}{|c|}{ Oral administration } & \multicolumn{2}{|c|}{ Transdermal administration } \\
\hline & Plasma & Synovial fluid & Plasma & Synovial fluid \\
\hline$C_{\max }, \mathrm{ng} \cdot \mathrm{mL}^{-1} /\left(\mathrm{mg} \cdot \mathrm{kg}^{-1}\right)$ & $2516 \pm 439$ & $2090 \pm 526$ & $20.2 \pm 7.2$ & $161.6 \pm 74.4$ \\
\hline $\mathrm{AUC}_{0-t}, \mu \mathrm{g} \cdot \mathrm{h} \cdot \mathrm{mL}^{-1} /\left(\mathrm{mg} \cdot \mathrm{kg}^{-1}\right)$ & $77.1 \pm 26.6$ & $71.0 \pm 23.6$ & $0.80 \pm 0.34$ & $5.54 \pm 2.83$ \\
\hline $\mathrm{AUC}_{0-\infty}, \mu \mathrm{g} \cdot \mathrm{h} \cdot \mathrm{mL}^{-1} /\left(\mathrm{mg} \cdot \mathrm{kg}^{-1}\right)$ & $80.0 \pm 27.6$ & $73.5 \pm 26.2$ & $0.95 \pm 0.41$ & $6.55 \pm 2.81$ \\
\hline
\end{tabular}

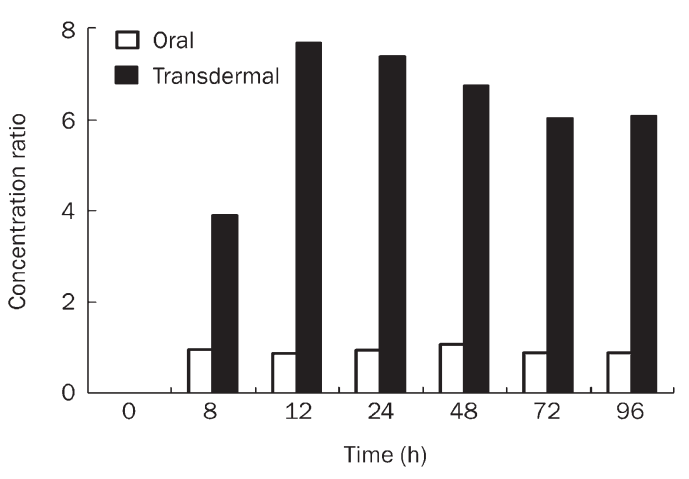

Figure 3. The concentration ratios of synovial fluid to plasma after oral and transdermal administrations for the treated leg to Beagle dogs $(n=6)$.

This may be due to the barrier properties of the skin, which may have resulted in the accumulation of the drug in the skin followed by sustained and controlled drug release. However, we observed one drawback of transdermal delivery, which was that the variability was larger than that for oral administration (Figures 1 and 2).

This result indicated the advantage of topical administration and also illustrated that the meloxicam concentration in SF following transdermal administration might serve as a better indicator than plasma concentration of the drug's therapeutic efficiency. The reported dose effects for meloxicam in horses corresponded to a plasma concentration between $130 \mathrm{ng} / \mathrm{mL}$ and $195 \mathrm{ng} / \mathrm{mL}^{[12]}$. Our results of SF concentrations higher than $100 \mathrm{ng} / \mathrm{mL}$ by transdermal administration should be adequate to meet therapeutic needs. On the other hand, transdermal administration is not suitable for rheumatoid arthritis in multiple joints, because the SF concentration of meloxicam in the untreated leg was much lower than the effective concentration (Table 4).

As shown in Figure 3, our experiment demonstrated that the $\mathrm{S} / \mathrm{P}$ ratios of topical administration were significantly higher than those of oral doses over the investigated period. This suggests the possibility of targeting drugs to local synovial tissues by topical delivery. These results are consistent with a previous study in which McNeill ${ }^{[13]}$ et al measured the muscle tissue-plasma concentration ratios of piroxicam following iv and topical administration in rats.

Our results indicated that accumulation of the drug in the $\mathrm{SF}$ of the untreated site occurred primarily by redistribution
Table 4. Plasma concentration and synovial fluid concentration of meloxicam in the treated and untreated joints of hind legs of Beagle dogs after transdermal administration of $1.25 \mathrm{mg} / \mathrm{kg}$ meloxicam to the right hind leg. $n=6$. Mean \pm SD.

\begin{tabular}{cccc}
\hline Time $(\mathrm{h})$ & $\begin{array}{c}\text { Synovial fluid concentration }(\mathrm{ng} / \mathrm{mL}) \\
\text { Treated } \\
\text { hind leg }\end{array}$ & $\begin{array}{c}\text { Untreated } \\
\text { hind leg }\end{array}$ & $\begin{array}{c}\text { Plasma } \\
\text { concentration } \\
(\mathrm{ng} / \mathrm{mL})\end{array}$ \\
\hline 8 & $78.4 \pm 19.8$ & $18.7 \pm 11.7$ & $20.1 \pm 9.33$ \\
12 & $167 \pm 60.2$ & $20.6 \pm 12.3$ & $21.8 \pm 10.1$ \\
24 & $124 \pm 113$ & $16.5 \pm 8.29$ & $16.8 \pm 8.32$ \\
48 & $62.2 \pm 25.7$ & $10.1 \pm 4.90$ & $9.22 \pm 4.85$ \\
72 & $37.6 \pm 16.5$ & $6.64 \pm 3.70$ & $6.24 \pm 2.90$ \\
96 & $22.3 \pm 6.61$ & $3.35 \pm 0.98$ & $4.24 \pm 2.38$ \\
\hline
\end{tabular}

from the systemic circulation. In contrast, most of the drug found in the SF of the treated site had been delivered by direct penetration from the dosage site, with only a small portion delivered by the systemic circulation. Similar conclusions can be found elsewhere ${ }^{[8,10,14]}$. All of these observations imply that cutaneous circulation is not always an infinite "sink," and that a drug may not be completely removed from the stratum corneum, epidermis, and dermis.

The results of this study indicate that meloxicam at therapeutic dosages can be delivered through a transdermal route. One major advantage of this method of delivery over traditional oral methods is that meloxicam applied topically could achieve desirable concentrations in the SF while maintaining a low plasma concentration. This low systemic exposure could provide numerous potential benefits to patients, including the avoidance of gastrointestinal tract irritation and reduced risk of serious adverse cardiovascular effects. Moreover, drug targeting to the SF was significantly improved with topical application to the affected joint region. Finally, the prolonged MRT indicated that transdermal administration resulted in controlled drug delivery over a longer period as the skin served as a drug reservoir.

In conclusion, we demonstrated that low systemic absorption and significant accumulation of meloxicam in the SF can be achieved through transdermal delivery. The use of transdermal delivery of meloxicam for the treatment of rheumatoid arthritis and other topical inflammatory conditions is therefore feasible, given that a desirable accumulation of meloxicam in the SF occurs via direct penetration from the drug treatment site. 


\section{Author contribution}

Professor Da-fang ZHONG and Dr Yue YUAN designed the study, Yue YUAN and Xiao-yan CHEN performed the experiments, San-ming LI and Xiu-yan WEI contributed new reagents or analytic tools, Yue YUAN analyzed the data and wrote the paper, and Hui-min YAO assisted in data analysis.

\section{References}

1 Davies NM, Skjodt NM. Clinical pharmacokinetics of meloxicam. Clin Pharmacokinet 1999; 36: 115-26.

2 Singh G, Lanes S, Triadafilopoulos G. Risk of serious upper gastrointestinal and cardiovascular thromboembolic complications with meloxicam. Am J Med 2004; 117: 100-17.

3 Noble S, Balfour JA. Meloxicam. Drugs 1996; 51: 424-30.

4 Gupta SK, Bansal P, Bhardwaj RK, Jaiswal J, Velpandian T. Comparison of analgesic and anti-inflammatory activity of meloxicam gel with diclofenac and piroxicam gels in animal models: pharmacokinetic parameters after topical application. Skin Pharmacol Appl Skin Physiol 2002; 15: 105-11.

5 Bevis PJ, Bird HA, Lapham G. An open study to assess the safety and tolerability of meloxicam $15 \mathrm{mg}$ in subjects with rheumatic disease and mild renal impairment. Br J Rheumatol 1996; 35: 56-60.

6 Lee CM, Maibach HI. Deep percutaneous penetration into muscles and joints. J Pharm Sci 2006; 95: 1405-13.
7 Heyneman CA, Lawless-Liday C, Wall GC. Oral versus topical NSAIDs in rheumatic diseases. Drugs 2000; 60: 555-74.

8 Singh P, Roberts MS. Skin permeability and local tissue concentrations of nonsteroidal anti-inflammatory drugs after topical application. J Pharmacol Exp Ther 1994; 268: 144-51.

9 Li YJ, Pan Y, Xu H, Wei G, Zheng JM. Pharmacokinetics and local tissue disposition of piroxicam following topical and oral application in rats. J Chin Pharm Sci 2002; 11: 85-90.

10 Suh H, Jun HW, Dzimianski MT, Lu GW. Pharmacokinetic and local tissue disposition studies of naproxen following topical and systemic administration in dogs and rats. Biopharm Drug Dispos 1997; 18: 623-33.

11 Yuan $Y$, Chen XY, Zhong DF. Determination of meloxicam in human plasma by liquid chromatography-tandem mass spectrometry following transdermal administration. J Chromatogr B 2007; 852: 650-4.

12 Toutain PL, Cester CC. Pharmacokinetic-pharmacodynamic relationships and dose response to meloxicam in horses with induced arthritis in the right carpal joint. Am J Vet Res 2004; 65: 1533-41.

13 McNeill SC, Pot ts RO, Francoeur ML. Local enhanced topical delivery (LETD) of drugs: Does it truly exist? Pharm Res 1992; 9: 1422-7.

14 Hui X, Anigbogu A, Singh P, Xiong G, Poblete N, Liu P, Maibach HI. Pharmacokinetic and local tissue disposition of $\left[{ }^{14} \mathrm{C}\right]$ sodium diclofenac following iontophoresis and systemic administration in rabbits. J Pharm Sci 2001; 90: 1269-76. 